\title{
TENDENCIAS PRODUCTIVAS EN EL SECTOR AGRÍCOLA CHAQUEÑO EN LA POST CONVERTIBILIDAD
}

\author{
Cristina Valenzuela y Angel Vito Scavo
}

\section{Introducción.}

El objetivo general de este análisis es el de aportar conocimientos para la comprensión de la dinámica territorial actual de la actividad agrícola en una provincia periférica del norte Argentino. El concepto básico que sustenta este propósito parte del enfoque del territorio como el resultado espacial de un legado histórico que cristaliza en un entramado de relaciones en constante reconfiguración por la dialéctica de procesos políticos, económicos y sociales que tienen lugar en el presente. A su vez, la comprensión de la amplitud y variedad de "respuestas" territoriales precisa tres conjuntos de acciones para su análisis. En primer lugar requiere un estudio pormenorizado de los procesos que dieron origen a la trama territorial actual. Luego es preciso analizar las modalidades de actuación de los individuos y organizaciones (agentes) que protagonizaron la vida económica en el transcurso de esos procesos para, en una tercer instancia, distinguir los efectos resultantes de la construcción de la trama territorial, en tanto elementos de índole estructural consolidados y que condicionan la dinámica contemporánea de ese producto histórico.

El resultado del análisis se apoya fundamentalmente en fuentes primarias (entrevistas en profundidad, parcialmente estructuradas a productores considerados informantes clave y representantes de organizaciones sociales) y en fuentes periodísticas, estadísticas, bibliográficas y documentales relativas al tema. El texto se estructura en tres partes: una primera sección que especifica la orientación metodológica, una segunda donde se contextualizan las transformaciones del sector agrario Argentino en los últimos 15 años y la tercera donde se analiza la compleja dinámica que incluye las nuevas tendencias de la producción de soja y las modalidades de la "resistencia" que sostienen los pequeños y medianos algodoneros ante el avance de ésta.

El trasfondo más amplio en el que se inserta este análisis remite a la discusión acerca de la viabilidad de alternativas productivas que reflejan identidades territorialmente arraigadas, que pueden actuar como recursos para el desarrollo si se posibilita a través de las instituciones, su coexistencia no antagónica con otras lógicas productivas.

\section{1) Principales instrumentos conceptuales. La construcción de la trama territorial.}

Sánchez Hernández, (2003: 215) señala que en cualquier discurso referido al signo de nuestros tiempos es posible apreciar la renovada atención de la sociedad por "las cuestiones relativas al territorio y a la identidad forjada en torno al apego por el marco geográfico de vida" como asuntos de indiscutible interés social. Se busca ofrecer una explicación 
articulada y multiescalar de los procesos territoriales que conciernen a la sociedad que los cimienta y transita. A su vez, la consideración de niveles de acción -individual y colectivaen los cuales se construyen esas cuestiones exige una especificación conceptual acerca de la variedad de escalas jerárquicas en las que se organizan las actividades humanas, la cual implica en su esencia discordancias entre fuerzas de magnitudes e impactos diferenciales -y significativas diferencias con las escalas dominantes hace dos o tres décadas atrás ${ }^{1}$.

El territorio como resultado espacial de un legado histórico cristaliza en un entramado de relaciones en constante reconfiguración por la dialéctica multiescalar de procesos políticos, económicos y sociales que tienen lugar en el presente. De ese resultado, nos interesa particularmente un aspecto, que Bourdieu (2000:19) distingue como “...el conjunto de las disposiciones del agente económico como producto paradójico de una larga historia colectiva reproducida sin cesar en las historias individuales..., , inscriptas paralelamente en estructuras sociales y cognitivas, en esquemas prácticos de pensamiento, percepción y acción. La dialéctica individual y colectiva entre el territorio y sus habitantes, con sus preferencias y necesidades, previsiones, esperanzas y posibilidades "...dependen de una historia, que es la misma del cosmos económico en que se exigen y recompensan..." (Bourdieu: 2000: 22).

Esa historia involucra una permanente interacción, tanto en términos de cooperación como de competencia, entre agentes y organizaciones (empresas, asociaciones, Estado) que constituyen una red de relaciones en constante transformación. Como precisa Sánchez Hernández (2003: 121) "Los mercados se construyen socialmente y el comportamiento económico forma parte de redes de relaciones entre agentes de naturaleza social" y en consecuencia “...esta naturaleza social y cultural de las redes condiciona la capacidad de aprendizaje y adaptación de los agentes que las integran, y con ella, su solvencia para tomar decisiones acertadas en un mundo caracterizado por la información asimétrica, la incertidumbre y la racionalidad imperfecta”. A partir del giro cultural, la Geografía Económica persigue la explicación de las modalidades de actuación de los individuos y organizaciones que protagonizan la vida económica en lugares concretos, resaltando por medio del trabajo de campo las especificidades locales, el estudio micro como medio de captación de las particularidades territoriales que condicionan el cómo de la actividad económica (Idem., 135).

Desde la perspectiva explicitada el objetivo es examinar la coexistencia territorial de dos lógicas de actuación sustentadas por agentes diferenciados en sus motivaciones, posibilidades y expectativas. En estas lógicas, (observables en las estrategias de uso del suelo) es posible identificar una interacción de fuerzas desiguales que cristaliza en

\footnotetext{
${ }^{1}$ David HARVEY, (2003: 101) advierte sobre la necesidad de estudiar los hechos en distintas escalas, como una garantía de amplitud en cualquier enfoque y para evitar sobredimensionar la importancia puntual de factores o elementos, siendo que “....un error común tanto de la interpretación analítica como de la acción política se produce porque demasiado a menudo nos encerramos en una sola escala de pensamiento...El resultado final es que todas las formas de pensar que operan sólo en una escala se vuelven al menos cuestionables, si no directamente engañosas".
} 
manifestaciones tanto de aceptación como de discrepancia a los impulsos en juego. Aplicando la idea al caso que nos ocupa, la lógica de la "resistencia" que sostienen los esquemas tradicionales de tipo familiar arraigados históricamente en el espacio productivo del Chaco no se opone a las nuevas tendencias difundidas en los últimos diez años, sino que aspira a una pervivencia digna, en un planteo de reproducción de opciones con un fuerte componente identitario asociado al cultivo del algodón. Por su parte, a lógica de adopción de las nuevas tecnologías de insumos y procesos de los cultivos transgénicos presiona por imponerse a través del accionar de nuevos agentes que se incorporan al territorio con una dinámica distinta.

Para llegar a la comprensión de esta dinámica es preciso contextualizarla por medio de la historia multiescalar de la trama territorial, lo cual implica examinar el contexto nacional para luego bajar a la dinámica provincial y en última instancia, llegar a la escala del individuo con el estudio de casos para completar el análisis y la interpretación de las diferentes posturas de los agentes que construyen esa trama.

\section{2) El contexto nacional : características distintivas y transformaciones del sector agrario Argentino en los últimos 15 años.}

En un país donde la actividad agropecuaria fue y sigue siendo la principal fuente proveedora de divisas, la producción de granos y carnes concentrada en la región Pampeana ${ }^{2}$ ha sido históricamente responsable del $60 \%$ de la producción agropecuaria y del 80\% de las exportaciones ${ }^{3}$, con una gravitación decisiva en el funcionamiento de todo el sistema económico nacional. Esa especialización explica en parte la concentración territorial de la producción, que se ha mantenido más o menos constante en las últimas cuatro décadas siendo cinco jurisdicciones (Buenos Aires, Ciudad de Buenos, Córdoba, Santa Fe y Mendoza) las que sumaban el 80\% del PBG en el año 2000. En contraposición, varias jurisdicciones (Chaco, Corrientes, Entre Ríos y Tucumán) disminuyeron su participación

\footnotetext{
${ }^{2}$ Región que GIBERTI (2001:121) delimita señalando que abarca casi 60 millones de hectáreas contenidas aproximadamente en un territorio delimitado por un radio de 550-600 kilómetros con centro en la Capital Federal. Esta área una de las seis regiones potencialmente más agroproductivas del mundo. Dice GIBERTI (2001:122): "Ecológica y económicamente, cabe, entonces hablar de dos Argentinas agropecuarias. Con máxima simplificación, nuestra unidad política nacional encierra por lo menos dos ámbitos muy distintos: uno de excepcional aptitud para producciones de clima templado, y otra sin mayores ventajas internacionales. La misma eficiencia empresaria lograría muy distintos resultados en una u otra de esas dos Argentinas, políticamente imaginarias pero económicamente reales debido al modelo de desarrollo histórico. A ello se suman significativas diferencias de tipo estructural en los procesos de producción y su respectiva gestión, en la estructura social y en la constelación de agentes económicos y su vinculación con quienes operan fuera de sus límites y en el perfil del modelo político administrativo local de las "economías regionales", (ROFMAN,1999:107).

${ }^{3}$ Los productos de origen agropecuario (primarios y MOA) aportaron a principios de 2000 el $50 \%$ de las exportaciones totales del país. Entre 1990 y 2000 las exportaciones de estos rubros aumentaron un 66\%. Para ampliar la información ver: Coord:IICA; Fortalezas y debilidades del sector agroalimentario; Esstudio 1.EG.33.7; Componente A; Préstamo BID 925/OC-AR. Pre II. Coordinación del Estudio: Oficina de la CEPAL-ONU en Buenos Aires, a solicitud de la Secretaría de Política Económica, Ministerio de Economía de la Nación.
} 
relativa, (Gatto y Cetrángolo, 2003: 25). También la distribución geográfica de la inversión exhibía un perfil territorialmente concentrado, donde 8 jurisdicciones absorbían el $90 \%$ de la inversión privada de las grandes empresas radicadas en el país a fines de los '90 (Gatto, F.; 2003: 114).

Un ligero análisis de las cifras del Censo Agropecuario Nacional de 2002 permite confirmar esa concentración territorial: La superficie agropecuaria sumaba un total de 174.808.564 hectáreas. De ese total, un 19,2\% correspondía a superficies implantadas, un $56,2 \%$ a pastizales naturales, un $19,7 \%$ a montes naturales y el $8 \%$ restante a superficie "no apta, no utilizada, con caminos y viviendas y sin discriminar". A su vez, de la superficie implantada a nivel nacional, en ese año (33.491.480 hectáreas), el 81,5\% se localizaba en las provincias pampeanas, repartiéndose el resto entre el $\operatorname{NOA}(7,2 \%)$, el NEA $(6,8 \%)$, Cuyo (3,9\%) y Patagonia (0,6\%).

En cuanto al destino principal de la superficie implantada en el país, dos tercios de la misma correspondían a cultivos anuales. De éstos, el grupo cereales y oleaginosas abarcaba el $60 \%$ del total. Considerando el ganado existente en el país en ese año, el 75\% de las 48.539.411 cabezas de bovinos se concentraban en las provincias pampeanas, situación similar para el caso del $71 \%$ del rodeo porcino y el $42,2 \%$ de los equinos.

En síntesis, el esquema productivo primario nacional se estructuró a partir de una región "central" dedicada a la producción de oleaginosas, granos y carnes y el examen de los complejos productivos confirma la continuidad de esta configuración ya que los más importantes (oleaginoso, bovino para carne y lácteos y cerealero) centralizan sus eslabones estratégicos -agroindustriales y de comercialización- en las provincias de Buenos Aires, Santa Fe, Córdoba y Entre Ríos. Esta concentración involucra también a producciones de tipo industrial como es caso del algodón, que es un complejo geográficamente desdoblado entre las provincias productoras de los fardos de fibra (Chaco, Formosa y Santiago del Estero con cultivo de secano y Salta, Catamarca y La Rioja con riego) y el corredor industrial Rosario-Buenos Aires donde se concentra la industria textil. También el caso del complejo bovino que incluye las actividades de cría, recría e invernada de ganado para faena es otro ejemplo de este desdoblamiento, ya que la dinámica del mismo implica el flujo de animales desde las zonas de cría con pasturas naturales (Nordeste) a los campos de invernada concentrados en el área pampeana.

El complejo oleaginoso genera el grueso de las exportaciones argentinas y ha tenido un crecimiento vertiginoso observable en sus exportaciones que aumentaron 17 veces entre principio de los años setenta y mediados de los noventa. Esta expansión se explica fundamentalmente por la soja. A nivel primario, el dinamismo de este cultivo se asentó en la conjunción de un paquete tecnológico nuevo, un contexto de precios internacionales favorables y el financiamiento para adquirir insumos y tecnologías adaptables localmente. Esto llevó a un primer salto en la producción a mediados de los noventa. Estructuralmente tendieron a consolidarse tanto una mayor tecnificación agraria (con el uso de fertilizantes, siembra directa y biocidas) como una clara tendencia a la tercerización de operaciones junto con el desarrollo de una amplia red de subcontratistas. El despegue fue impulsado por la duplicación del precio internacional de las semillas oleaginosas y del aceite, lo que hizo 
muy rentable la producción de ambos; también por el fuerte aumento del rendimiento por hectárea en los últimos 20 años (de $2.2 \%$ anual en la soja y de $4.0 \%$ anual en el girasol) y por la factibilidad de hacer un doble cultivo, de trigo en el invierno y de soja en el resto del año, lo que duplicó la rentabilidad de la tierra. En el transcurso de la década de los noventa fue extraordinaria la expansión del complejo oleaginoso-cerealero hacia provincias con baja tradición en estos rubros, que incorporaron estos cultivos y abandonaron producciones específicas históricamente arraigadas.

La especialización agropecuaria de las áreas extra-pampeanas ${ }^{4}$ en productos singulares o complementarios de la producción pampeana como resultado -en muchos casos- de una historia relativamente reciente, no fue un proceso neutro sino que respondió a intereses económicos vinculados a las etapas del desenvolvimiento económico del país, que contribuyeron a constituir un mosaico sumamente diferenciado de estructuras abastecedoras de productos específicos para la etapa agro-exportadora primero, y el mercado interno después. En algunos casos estos complejos exhibieron históricamente la ausencia de tramas comerciales eficientes, con oligopolios procesadores, una escasa articulación interempresarial y una baja inserción externa. La regulación estatal directa o indirecta posibilitó la supervivencia de una amplia constelación de agentes productivos que exhibieron una adaptación desigual a la reorientación macroeconómica de los últimos 15 años, con la apertura y desregulación ${ }^{5}$.

La producción algodonera constituye un ejemplo de un complejo productivo y empresarial con serios déficit en sus eslabonamientos físicos y en su entramado social e institucional que afectan fuertemente su desempeño agregado y la propia evolución de las

\footnotetext{
${ }^{4}$ Frente a las ventajas naturales de la región pampeana, el Nordeste presenta una serie de características climáticas que resultan limitativas para los cultivos de cereales y oleaginosas. Estas limitantes están relacionadas con el régimen anual e interanual de precipitaciones. El primero registra una mayor concentración estacional en el Nordeste, con precipitaciones estivales y sequía invernal y el segundo exhibe una marcada variabilidad interanual. En relación con el límite climático con la Pampa, Bruniard (1981: 279 y 310) resalta una zona crítica, localizada aproximadamente entre $\operatorname{los} 30^{\circ}$ y $32^{\circ} \mathrm{S}$., "que si bien no constituye una ruptura espectacular, adquiere el carácter de un verdadero límite climático, si consideramos su persistencia, la simultaneidad de sus efectos y su carácter complejo. ...Esta franja es indicativa también del límite meridional de los cultivos subtropicales como la caña de azúcar, el algodón y el tabaco “. A esta discontinuidad se suma un gradiente hídrico de variación longitudinal que opone al ambiente húmedo del oriente del Nordeste con el occidente donde los déficits hídricos adquieren valores destacados en los períodos invernales. Estas características conjugan un ambiente natural riguroso, menos "estable" que el ámbito pampeano, el cual exhibe una menor oscilación anual e interanual de las precipitaciones, con un régimen pluviométrico de pradera, carente de períodos de déficit hídrico.

${ }^{5}$ Los cambios en el sector agrícola Argentino se aceleraron en 1991 con la implementación del Plan de Convertibilidad, un nuevo programa económico que significó un punto de ruptura en la evolución de la economía argentina. El mismo tenía cuatro pilares fundamentales: la ley de convertibilidad, la desregulación de la actividad económica, las políticas de privatizaciones y la apertura externa, (Ghezán, Mateos y Elverdín; 2001:7-8). Los años siguientes significaron el debilitamiento de la institucionalidad que caracterizaba a la intervención estatal en la agricultura y en el medio rural cuyos efectos se potenciaron por su combinación con la tendencia expansiva de los agronegocios, y la creciente integración del sector agrícola a los complejos agroindustriales. Igualmente importantes fueron las políticas de descentralización, orientadas a otorgarle mayor autonomía a instancias de gestión local y regional, (Sepúlveda, et al. 2003:17 y 24).
} 
empresas. Los integrantes de la cadena en forma secuencial son los productores de fibra, desmotadores, hilanderos, tejedores, tintoreros y confeccionistas, a los que se agregan los comerciantes que actúan según las circunstancias y el grado de integración vertical existente entre los distintos eslabones. Una de las características más llamativas de este complejo a escala nacional es que la producción agraria está localizada en Chaco, Formosa y Santiago del Estero y los eslabones industriales están disociados espacialmente en dos áreas: el corredor industrial Rosario-Buenos Aires y las provincias de San Luis, La Rioja, Catamarca, San Juan y Tucumán donde el eslabón textil se asentó a partir de lo ochenta, obedeciendo a estímulos fiscales.

\section{1) La dinámica comercial externa en la post convertibilidad.}

En términos económico-comerciales el Mercosur significó para la economía Argentina un aumento de su comercio exterior en los noventa. La coexistencia de sistemas cambiarios distintos entre Argentina y Brasil, los principales socios del Mercosur, a partir de la devaluación del real en enero de 1999 y los consecuentes problemas comerciales bilaterales no posibilitaron el abordaje de las cuestiones vinculadas a las complementariedades de los aparatos productivos así como tampoco la definición de estrategias comerciales comunes respecto de terceros mercados, (Figueroa y Villapando, 2003: 119).

La devaluación del peso argentino en 2002, el contexto de precios internacionales favorables a los productos como la soja y los nuevos escenarios de negociación comercial (ALCA y Unión Europea) configuraron un contexto de reactivación que se dio en llamar "el salto exportador argentino". Según el Centro de Estudios para la Producción 6 entre 2002 y 2005 las ventas totales al exterior subieron un $56 \%$ al pasar de 25.651 a 40.013 millones de dólares. Este "salto exportador" se acompañó con una expansión vigorosa del consumo y la inversión en el marco de una posición fiscal superavitaria. Entre 2002 y 2005 los productos primarios y las MOA (manufacturas de origen agroindustrial) contribuyeron con el 53\% del total de exportaciones. Dentro de las MOA, la significación del complejo sojero es muy notable, ya que Argentina junto con Estados Unidos y Brasil constituyen los tres grandes protagonistas de este rubro.

La mayoría de los complejos productivos nacionales encontró en la salida exportadora la oportunidad de crecimiento. Las dificultades se advirtieron en los primeros eslabones de los circuitos extra-pampeanos, áreas rurales especializadas en productos tradicionales de las provincias periféricas con escasas posibilidades de inserción en la dinámica exportadora y de agronegocios. Estas estructuras productivas regionales mostraron respuestas pasivas o regresivas, de tipo defensivo, para sobrevivir productivamente en precarias condiciones, con situaciones de endeudamiento crítico ${ }^{7}$. Es el caso del Chaco, que

\footnotetext{
${ }^{6}$ Secretaría de Industria, Comercio y de la Pequeña y Mediana Empresa. http://www.industria.gov.ar/cep/ pancomexterior/estudios/2006/52_salto\%20exportador.pdf

${ }^{7}$ La estructura de funcionamiento de los más destacados circuitos productivos instalados en la periferia del espacio regional, caracterizada por la coexistencia de agentes económicos con un muy desigual poder de negociación se mantuvo inalterada luego de la devaluación, (Rofman, 2003: 392). Como señala este autor “con excepción de la yerba mate, no se restablecieron mecanismos de intervención directa o indirecta del
} 
a partir de 1998 dejó de ser la principal provincia algodonera argentina para incorporarse a la producción de soja transgénica. Este cambio fue el más importante en el desenvolvimiento del sector agrícola provincial, porque significó el relegamiento del “oro blanco", el cultivo que sustentó la ocupación y organización económica del territorio Chaqueño desde 1920. Este proceso que nos ocupa, constituye como señala Aparicio, (2005: 210) “...el ejemplo más dramático de las reestructuración de la agricultura argentina" 8 .

\section{3) Evolución de las tendencias productivas en el sector agrícola Chaqueño.}

Para los cultivos industriales localizados en su mayoría en las economías regionales ${ }^{9}$ (vid en Cuyo, caña y tabaco en el Noroeste, algodón, yerba mate y té en el Nordeste) el mercado nacional fue el impulsor histórico de su expansión económica. La producción solamente accedía al mercado externo como sobrante del consumo interno y, por ende, el sistema de precios que la regulaba no dependía de las cotizaciones internacionales, sino de la dinámica del consumo local y de la intervención reguladora del Estado. (Rofman, 1999:109). Así, el Chaco, se especializó en cultivos anuales (algodón fundamentalmente) con sistemas de secano concentrados en el centro y sudoeste provincial.

El algodón fue el cultivo por excelencia de los pequeños y medianos productores desde 1920. La coexistencia de una amplia constelación de agentes productivos en un equilibrio precario fue posible gracias a la intervención estatal directa o indirecta. Con la desregulación y apertura de la economía en los '90 esta producción especializada quedó sin protección ante los vaivenes de los precios en el mercado internacional. A mediados de esa década, si bien todos los agricultores se volcaron a producir algodón, el extraordinario incremento de la productividad y la elevación de los rendimientos obedecieron a las innovaciones tecnológicas incorporadas en los estratos de medianos y grandes productores. La producción creció mediante la difusión de sistemas mecanizados de cosecha, la introducción de nuevas variedades de mayor rendimiento y calidad y más precocidad en su desarrollo -que acortaron el ciclo de cultivo y redujeron el período de recolección- y la ampliación del parque industrial de primera transformación. Nuevas desmotadoras instaladas en este período en la provincia encabezaron el proceso exportador donde Brasil implicaba el $90 \%$ de los envíos chaqueños.

Mientras se difundía la soja RR en el área pampeana, la euforia algodonera chaqueña se veía truncada por el descenso de los precios internacionales y las inundaciones ocurridas entre septiembre de 1997 y abril de 1998. Las perspectivas alentadoras dejaron

Estado en segmentos de dichos circuitos donde antes de los '90 regían mecanismos de regulación estatal o de autorregulación de precios".

8 Era la actividad con mayor incidencia de explotaciones familiares, las que llegaron a proveer cerca del $40 \%$ de la producción. En la campaña 2002-2003, la superficie total con algodón del país era la décima parte de la que se cultivaba hace 10 años. Subsistieron los productores que pudieron incorporar las nuevas variedades y la cosecha mecánica...".. APARICIO, Susana (2005: 210).

9 Entendidas, según Rofman (1995:229), como el conjunto de espacios de inserción periférica, de menor nivel de desarrollo relativo y con un comportamiento histórico subordinado a las políticas y procesos dominantes asentados en el "centro" del país. 
paso a una crisis muy grave, por la magnitud del endeudamiento de pequeños y medianos productores, (poseedores de explotaciones de menos de 100 hectáreas y de 101 a 200 hectáreas, respectivamente). El deterioro se fue agudizando, los precios pagados por tonelada de algodón al colono, (que venían descendiendo desde $1997^{10}$ ) cayeron aún más, los montos de las deudas de las cooperativas se incrementaron hasta llevarlas a la quiebra ante la imposibilidad por parte de los socios de cumplir con sus obligaciones crediticias y las cosechas algodoneras a partir de 1999 fueron las peores en la historia del país. En ese contexto, los menores costos de implantación y la difusión de la siembra directa fueron los factores dominantes para la expansión de distintas variedades de soja en la provincia, “...en un peligroso esquema de monocultivo que muchos dieron en llamar la sojarización de los campos chaqueños”. (NORTE RURAL, 8/10/2003).

La expansión de distintas variedades de soja determinó la coexistencia de dos sistemas productivos muy distintos: la soja genéticamente modificada (RR) con el paquete tecnológico biocidas-siembra directa, precios estables y comercialización segura en explotaciones medianas y grandes con modelos de manejo empresarial, y el algodón en unidades predominantemente familiares con diversos grados de capitalización y sistemas tradicionales de producción, mayores costos y falta de transparencia en el mercado de precios.

El proceso de difusión e incorporación masiva de la soja centró su dinamismo en la ampliación de las fronteras cultivables y en mecanismos especulativos de tenencia temporal de la tierra y generó un nuevo modelo de organización de la producción primaria conformando sobre la base de un fuerte predominio de la oferta de insumos ofrecidos por un número acotado de oferentes internacionales y sustentado por redes de distribución comercial privada. La elevación de la escala económica y de las exigencias de capital requeridas para dedicarse a la agricultura, aceleró la exclusión de los productores que por su situación de endeudamiento no pudieron elegir.

Con la expansión de las fronteras productivas tras la oleaginosa, en el Chaco se superó el millón y medio de hectáreas sembradas incursionando en áreas "no tradicionales" como los departamentos Almirante Brown y General Güemes, que abarcan todo el extremo noroeste, (un $42 \%$ de la superficie provincial) y contienen al monte "Impenetrable"

${ }^{10}$ Uno de los aspectos que tiene una fuerte incidencia en la formación del precio pagado al colono por el algodón son los altos costos operativos que tienen las desmotadoras consideradas obsoletas en función de su capacidad de producción fardo/hora, consumo -y deuda- energética, capacidad económico-financiera para la compra de algodón en bruto y la gestión empresarial de venta. Al respecto, destaca E. CEPEDA que las desmotadoras de las cooperativas Chaco tuvieron a principios de los '90 como valores promedio los setenta pesos por tonelada de algodón en bruto desmotada más la semilla que quedaba en manos del industrial que procesaba el algodón en bruto. Para el año 2000 era considerado como "muy razonable" pagar entre treinta a treinta y cinco pesos por tonelada desmotada en las modernas usinas que se instalaron en la "primavera algodonera" del 94-96. En: Alta concentración de acopio en pocas industrias y escasa demanda laboral. Cepeda, Edgardo. SUPLEMENTO NORTE RURAL, del miércoles 16 de febrero de 2000, pág. 5. Resistencia, Chaco.

${ }^{11}$ La comparación de los datos estadísticos de los Censos Nacionales agropecuarios de 1988 y 2002, a nivel departamental demuestra que el área algodonera (centro-sudoeste) perdió más de 2.000 explotaciones y el 
posibilidades ciertas de obtener dos cosechas por año agrícola, además de los bajos costos para acceder a la tierra fueron los ejes de esa ampliación protagonizada por productores y empresarios del centro del país que en significativa corriente migratoria y alta capacidad de producción, arrendaron o adquirieron la mayoría de los campos con superficies superiores a las 500 hectáreas. Estos nuevos actores oriundos y residentes en provincias del área pampeana introdujeron un conjunto de modernas modalidades y encontraron en el área sudoeste del Chaco extensiones suficientes para expandirse. La prensa provincial describió el fenómeno como “...la invasión de productores ajenos a la provincia que compraron o alquilaron tierras y se dedican a la producción de soja. Es evidente que la vocación de esta gente es producir soja y no algún cultivo alternativo. La incógnita se basa en saber si este cambio estructural no tiene retorno, es circunstancial y puede ser revertido, y sobre esa base se puede pensar en volver a incrementar el cultivo de algodón o no". (Larramendy, Juan Carlos. En: Suplemento NORTE RURAL del miércoles 2 de julio de 2003, Pág. 7).

Considerando los dos últimos censos nacionales agropecuarios, el área algodonera ${ }^{12}$ registró entre 1988 y 2002, una disminución de 1957 explotaciones. Este total encubría dos tendencias: por una parte un aumento de 181 explotaciones de más de 500 hectáreas y por otra parte la tendencia más notoria que fue la disminución de 2138 explotaciones entre 1988 y 2002 para los estratos inferiores a las 500 hectáreas. A su vez dentro del gran grupo, el número de explotaciones de menos de 100 hectáreas disminuyó en 1439 explotaciones en ese período.

\begin{tabular}{|l|c|c|c|}
\hline Variación en el número de exportaciones en el área algodonera del Chaco \\
\hline & $\mathbf{1 9 8 8}$ & $\mathbf{2 0 0 2}$ & \\
\hline Menos de 100 hectáreas & 4066 & 2627 & $\mathbf{- 1 4 3 9}$ \\
\hline de 100 a 500 & 2909 & 2210 & -699 \\
\hline 500 a 1000 & 392 & 431 & 39 \\
\hline Más de 1000 & 178 & 320 & 142 \\
\hline TOTAL & 7545 & 5588 & $\mathbf{- 1 9 5 7}$ \\
\hline
\end{tabular}

Fuente: Censos Nacionales Agropecuarios de 1988 y 2002, INDEC. República Argentina

El mayor impacto de la crisis algodonera y de la difusión de la soja lo sintió el sector agrícola de pequeños (25 a 100 hectáreas) y medianos productores (de 101 a 200 hectáreas) que quedó altamente endeudado a fines de los ' 90 . El endeudamiento ${ }^{13}$ derivado

área con nuevos cultivos de soja (departamento General Güemes, en el oeste), recientemente desmontada incorporó más de 800 (ochocientas) explotaciones nuevas. La superficie agropecuaria provincial se incrementó en más de 400.000 hectáreas y la extensión de la unidad agropecuaria promedio aumentó de 302,6 a 365,8 hectáreas. La provincia perdió además, entre 1991 y 2001, 60.000 habitantes rurales.

${ }^{12}$ Constituída por los departamentos de Comandante Fernández, Chacabuco, 12 de octubre, F.J.S.M.de Oro, G. Belgrano, Maipú, M.L.Fontana, 9 de Julio y O Higgins.

${ }^{13}$ Son 1600 productores con $\$ 147.000 .000$ de deuda con el Banco Nación; ese monto es lo que sería para la Provincia de Chaco en pesos y número de productores. Son los que tienen calificación de 5 y 6 , que son los 
de la falta de pago de los créditos tomados con el Banco Nación Argentina, con acreedores privados, proveedores de insumos y acopiadores obedeció a los buenos pronósticos que se habían trazado para el algodón a fines de la campaña 1996/97. La apuesta hacia el futuro materializada en la toma de créditos para la modernización tecnológica, parecía en esos años el camino más lógico y aceptable. Esta "apuesta para adelante" fue una iniciativa común a los sectores agrícolas a escala nacional donde, como señala Bidaseca (2004: 410) “...el discurso de la "modernización" penetró en un principio cuando los hombres y mujeres del campo le adjudicaron credibilidad -"nos endeudamos porque creímos"-... pero más tarde se enfrentó a sus prácticas y erosionó sus propios valores y creencias provocando un cuestionamiento de la legitimidad de ese orden que aparecía como natural, estableciendo de ese modo una ruptura con el mismo".

CHACO. Superficies sembradas con algodón y soja. 1994-2004.

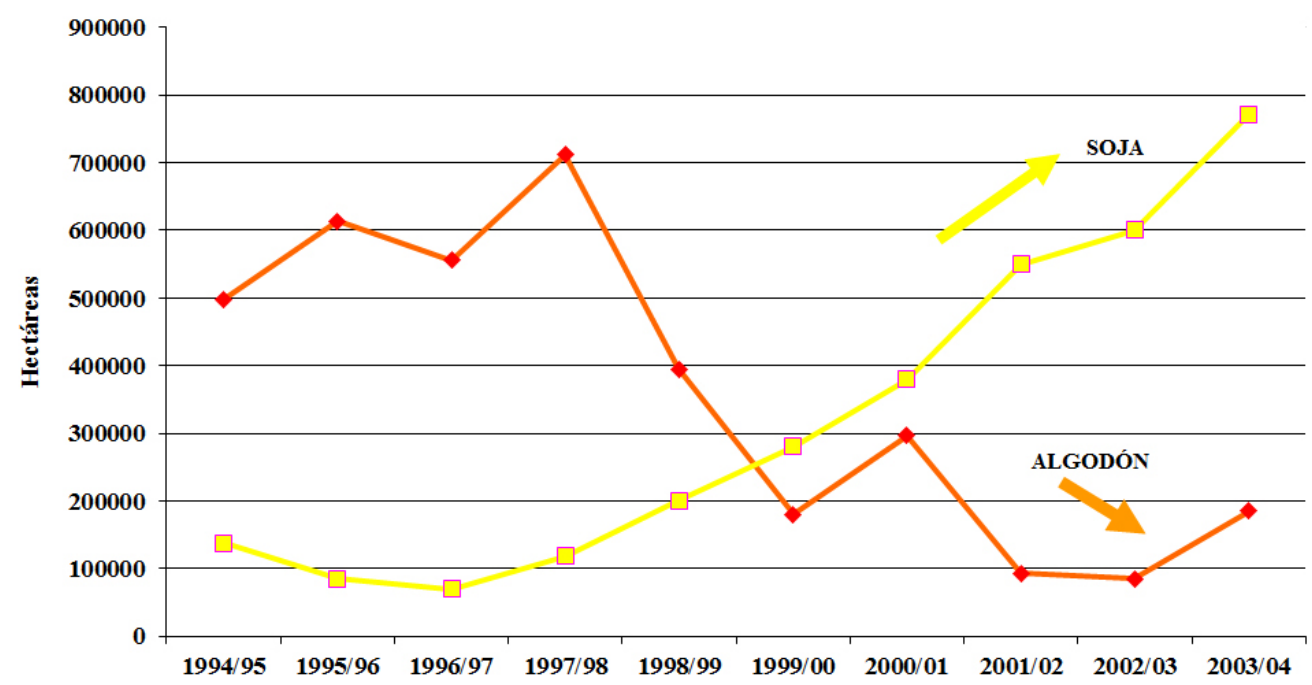

Fuente: Elaboración propia en base a datos obrantes en : PROVINCIA DEL CHACO. Ministerio de la Producción.Subsecretaría de Ganadería y Granja. Estadísticas Ganaderas y Granjeras. Resistencia, 1998 y 2004.

Estos estratos de agricultores Chaqueños imposibilitados de cumplir con las obligaciones contraídas y de obtener nueva financiación para seguir produciendo, abarcaban, en un 80 por ciento, a los poseedores de explotaciones con extensiones comprendidas entre 25 y 200 hectáreas y en el 70 por ciento de los casos, a productores de 51 a 75 años

créditos irrecuperables; pero en realidad ninguno es irrecuperable porque en sí persiguen el cobro, como están garantizados con hipotecas, son créditos recuperables. (Entrevista a Juana Vukich, realizada el 7 de julio de 2006 por Cristina Valenzuela y Liliana García) 
$\left(\right.$ Norte Digital, 16/11/2006) ${ }^{14}$. Estos segmentos, invalidados por la coyuntura, exhibieron distintas formas de "resistencia" para defender a sus familias de la pérdida de la tierra. Y esa "resistencia" que sostuvieron y aún sostienen, se sustentó en una identidad arraigada en varias generaciones que habían vivido según sus propias palabras "las penurias y las buenas cosas del campo en sus épocas de bonanza" 15 . No "resistir", entonces, no era una opción, ya que significaba sencillamente, traicionar esas raíces.

Las posturas y determinaciones de estos agentes constituyen el resultado de lo que Sánchez Hernández (2003:68) distingue como "las micro decisiones agregadas que configuran el orden social". Estas determinaciones transcurridas en un espacio compartido, "...encierran un componente colectivo de base territorial que coloca a la realidad geográfica en el centro de la explicación sobre la existencia misma de la acción colectiva, que se convierte en racional merced a su inserción en un contexto más amplio que el pura y estrictamente mercantil". Este componente, que podríamos denominar idiosincrásico, es recurrentemente identificable en el discurso de los productores residentes en el área algodonera tradicional del Chaco (Pampa Napenay, cercana a Roque Sáenz Peña, la capital nacional del algodón) considerados como "informantes clave". En sus expresiones se advierte una coincidencia general en la identificación con el cultivo que se practica en la zona desde hace más de 70 años:

- "Sembré algodón este año, porque es lo que sé hacer desde hace muchos años....Soy algodonero desde hace 40 años". . (Propietario de 29 hectáreas en Lote 33, Pampa Napenay).

- "Sembramos algodón este año porque somos algodoneros desde hace años. En mi familia hace 60 años que somos algodoneros". Yo comencé con el algodón en 1962, hace 45 años. (Propietario de 142 hectáreas en en Lote 33, Pampa Napenay).

-"Sembré 60 hectáreas de algodón este año, porque siempre se viene sembrando. Hace 26 años que soy algodonero". (Propietario de 300 hectáreas en el Lote 1, Colonia José Mármol ( La Montenegrina ).

A su vez, la "resistencia" de los algodoneros se materializó en el surgimiento de organizaciones sociales para la defensa de los productores quebrados y de la familia rural. Es el caso de la Organización Mujeres de la Producción (OMP), surgida a partir de la reunión de 5 mujeres pertenecientes a familias algodoneras, en la ciudad de Sáenz Peña, la segunda ciudad del Chaco y Capital Nacional del Algodón en enero del año 2001, fecha en que se constituyó el Estatuto del movimiento que se proponía luchar por "la protección,

\footnotetext{
${ }^{14}$ La deuda de origen de los productores con el Banco Nación no pasa de los 35 millones" Declaraciones de la diputada provincial, doctora Viviana Glibota. Norte Digital 16/11/06, 10:40 Hs. Disponible en: http:// visual03.visualhosting.net/ diario/.

${ }^{15}$ Entrevista a Juana Vuckich, tercera generación de productores algodoneros, el 7 de junio de 2006.
} 
el desarrollo y crecimiento de la familia rural, lograr la permanencia de la familia en el medio rural y mejorar su calidad de vida". (Entrevista a Juana Vukich, presidenta de la OMP, 23/11/06).

La motivación fundamental de este movimiento es la defensa de la identidad y de los estilos de vida, dado que en palabras de su Presidenta: “...la mayoría de nosotras somos productoras; algunas somos hijas de productores, nos hemos criado en el campo hemos vivido las penurias y las buenas cosas que ha tenido el campo en sus épocas de bonanza y hemos visto a nuestros padres arrodillados frente al cultivo, a veces, cuando las cosas no venian bien...entonces, era como traicionar nuestras raices", (Entrevista a Vukich, el 11/07/06).

Las motivaciones que tienen sus miembros para participar pueden explicarse a partir de mecanismos que ponen en juego para evitar la marginación, en el marco de una "política de identidad" reivindicativa que busca conservar, al mismo tiempo, el sentimiento local de pertenencia y la apertura hacia el mundo (Berdoulay, 2002: 59). El espacio como contenedor de la "memoria histórica" aparece como una primera explicación y, probablemente, la más comprensiva del conjunto de causas que dieron origen al movimiento, constituido por "...los que venimos de familias algodoneras, donde nuestros padres han sido "algodoneros de raza".

La confrontación inicial con los poderes públicos se concentró en detener el accionar del remate bancario (donde el principal acreedor es el Banco Nación) y de los acreedores privados, tratar de encontrar las vías de diálogo para renegociar las deudas que se acrecentaron desproporcionadamente y encontrar estrategias para tratar de solucionar el conflicto mediante acuerdos de pago, viendo la deuda de capital de origen y proponiendo una reparación para que no se pierda el suelo. Se trata de "pelear el monto de la deuda" al mismo tiempo que de "generar los recursos para cancelar nuestras obligaciones, porque sino es imposible, (Entrevista a Vukich, el 11/07/06). La evolución de la economía y la persistencia de las dificultades de los productores llevó a la OMP a precisar el pedido de "la reestructuración de la deuda de origen, teniendo como base de ello el capital registrado en la primera hipoteca del campo, además de pedirse la eliminación de intereses compensatorios, punitorios y el CER-Coeficiente de Estabilización de Referencia". (Diario Norte: 1/04/06).

La modalidad principal de reclamo ha consistido en las movilizaciones frente a sucursales del Banco Nación en el interior provincial, particularmente en aquellas localidades donde residen los productores endeudados que van a remate. La organización, según sus propios registros para noviembre de 2006, había logrado la reestructuración o cancelación de las deudas en 8 casos, el impedimento de 12 remates directos y de aproximadamente 50 ejecuciones. (Entrevista del 21/11/06).

La OMP amplió el discurso inicialmente circunscrito al tema del endeudamiento incorporando progresivamente una perspectiva integral de los problemas de los agricultores, sin que aquel primer eje reivindicativo fuera abandonado. Así, al planteo inicial de lucha se sumó el tema de seguridad rural, colaborando en la formación de un consorcio de 
productores afectados (COPEDER) a partir del cual se promovió la instalación de un destacamento policial en el departamento Independencia, donde el delito rural disminuyó notoriamente. También se incorporaron problemáticas relacionadas con la emergencia hídrica, el mejoramiento de caminos, la extensión de la electrificación rural, los problemas de desabastecimiento y el aumento de precio del gasoil y el mejoramiento de las condiciones edilicias de las escuelas, en el marco de una estrategia general de mejoramiento de las condiciones de vida de la familia rural.

El fantasma de la expropiación, es un tema recurrente en el discurso de la OMP. En este sentido, la mayor parte de las entidades del sector coinciden en señalar que la falta de una política nacional que atienda a las realidades regionales, lleva a las entidades bancarias a dar el mismo tratamiento a los productores chaqueños que a los de la Pampa Húmeda, cuando las realidades del norte del país son sustancialmente distintas a las del centro y sur de Argentina. El pedido de suspensión por un año de las ejecuciones y remates de campos y herramientas agrícolas y de una solución definitiva al problema del endeudamiento de los productores con la entidad bancaria oficial, llevó a principios de enero de 2006 a las agrupaciones relacionadas con la producción primaria (Mujeres de la Producción del Chaco, Sociedad Rural Argentina, Asociación Productores del Sudoeste, Federación Agraria Argentina Filial Sáenz Peña, Asociación de Productores Forestales), a convocarse frente a la sucursal del Banco de la Nación Argentina en la localidad de Campo Largo, ya que de esa sucursal habrían salido las primeras órdenes de remates y ejecuciones de campos de productores chaqueños, casos que fueron resonantes y que dieron inicio a la lucha de entidades agrarias para evitarlos ${ }^{16}$.

Como respuesta a la grave situación de los productores, surgió la ley 26.090, sancionada el 5 de abril y promulgada el 24 del mismo mes de 2006, declarando zona de Desastre y Emergencia Económica y Social para el período comprendido entre el 10/02/2006 al 30/ 11/2006 a determinados departamentos de la Provincia del Chaco ${ }^{17}$ y disponiendo la creación de un Fondo Especial de Emergencia. Esta ley establece un período de gracia de un año a los productores para el pago de las obligaciones impositivas y previsionales, además de la refinanciación de sus deudas hasta en 120 cuotas mensuales con quita de intereses resarcitorios y punitorios y eventuales condonaciones. La OPM junto con la Asociación de Productores del Sudoeste, se encontraban en septiembre de 2006 en tratativas para que, dentro del marco de esta ley, se establezca un subsidio para el sector agropecuario antes del vencimiento de la misma y teniendo en cuenta la crisis que

${ }^{16}$ La modalidad consistió en ubicarse frente al edificio del banco y colocar banderas y pasacalles frente a las puertas del mismo para impedir el normal funcionamiento de este, permitiendo solamente el ingreso de los jubilados que deben percibir sus haberes. El programa de protestas se realizó en distintas sucursales del BNA, con el objetivo de lograr la suspensión de los remates por un año, y mejores condiciones de reprogramación y recálculo de las deudas.

${ }^{17}$ Los departamentos de Comandante Fernández, Independencia, San Lorenzo, O’Higgins, Libertador General San Martín, General Belgrano, 9 de Julio, Chacabuco, 12 de Octubre, 25 de Mayo, Quitilipi, Presidencia de la Plaza, Sargento Cabral, Mayor L. J. Fontana, Fray Justo Santa María de Oro, Almirante Brown, General Güemes, Maipú, General Donovan, 2 de Abril, Tapenagá, Bermejo, $1^{\circ}$ de Mayo, Libertad y San Fernando, de la provincia del Chaco. 
está atravesando el sector en cuanto a las condiciones climáticas, el desabastecimiento y la suba del precio del combustible. Para julio de 2007, la Organización reclamaba al P.E.N. el compromiso del pago en tiempo y forma de un subsidio algodonero destinado a afrontar las labores de siembra.

Si bien el cultivo de algodón en la provincia inició una lenta recuperación de la superficie sembrada a partir de 2003 y el sostén de esta tendencia requiere una política sectorial firme y sostenida acordada a nivel nacional y provincial que implique apoyo crediticio, exenciones impositivas y convenios de vinculación tecnológica que posibiliten la reconstrucción del sector ya existente y promuevan la instalación de los eslabones ausentes del complejo en el $\mathrm{Chaco}^{18}$.

\section{4) Consideraciones Finales:}

Considerando que el desarrollo está asociado no sólo a la dotación de recursos y al tamaño de los mercados, sino fundamentalmente a un conjunto de esfuerzos y acciones de complementariedad tendientes a generar capacidades productivas y conocimientos especializados dentro de áreas geográficamente delimitadas, la puesta en práctica de esta premisa exige como punto de partida el diseño de una política integral que impulse el desarrollo productivo de las áreas marginales partiendo de la idea de que las ventajas comparativas se pueden crear y que por lo tanto tienen una naturaleza dinámica apoyada en gran medida en la voluntad expresa del Estado de desarrollar la trama institucional de rescate y sostén del territorio y su bagaje histórico.

La pretendida inclusión se justifica en la medida en que otorgue la prioridad debida a la participación económica de la población rural, no para privilegiar formas precarias de producción sólo porque éstas son las que predominan en una región, sino mediando la aceptación de que las realidades locales exigen distintas estrategias de respuesta que reconozcan -en una primera instancia- sus necesidades específicas. La voluntad institucional de evitar la marginación debe además reconocer una identidad que es el resultado de miles de "vidas vividas en un lugar" (Harvey, 2007: 191). Ello no implica el diseño de "pobres estrategias para pobres”, (Sepúlveda, 2003) sino el rescate de tradiciones que resisten, sustentadas sentimientos de pertenencia arraigados en la memoria colectiva de los productores.

\footnotetext{
${ }^{18}$ Como es el caso de la construcción iniciada a fines de 2006 de la fábrica textil de la firma Santana Chaco Textil S.A, la cual con una inversión superior a los 98 millones de pesos y generando más de 300 puestos de trabajo, con tecnología de punta hace suponer el inicio de un proceso de reposicionamiento del Chaco en la cadena de valor de la producción textil. Santana Textil está radicada en Fortaleza, al Norte de Brasil, se inició como una empresa familiar, se fue expandiendo y generó múltiples empresas familiares que trabajan en confección alrededor de la producción textil de Santana. En Natal tienen otra planta donde el 100\% de su producción se envía al departamento de Pernambuco, donde se transforman las telas en prendas de vestir. Si bien parte de su producción ya se vende en la Argentina, el Chaco se constituye ahora en el primer lugar del mundo, elegido entre varias provincias, por el grupo empresario Santana Textil para radicarse fuera del Brasil.
} 


\section{Bibliografia}

Aparicio, Susana. Trabajos y trabajadores en el sector agropecuario de la Argentina. En: El campo argentino en la encrucijada. Estrategias y resistencia sociales, ecos en la ciudad. Norma Giarraca y Miguel Teubal (coordinadores).Buenos Aires, 2005. Alianza Editorial.

Besil, Antonio. 2002. La nueva crisis algodonera ¿Crisis coyuntural o cambio estructural en la agricultura chaqueña?. En: Indicadores Económicos . Publicación del Dpto. de Economía de la Facultad de Ciencias Económicas de la Universidad Nacional del Nordeste. Año 11. Número 49. Diciembre.

Berdoulay, Vincent. Sujeto y acción en la Geografía Cultural: El cambio sin concluir. En: Boletín de la A.G.E.N ${ }^{o}$ 34. 2002. Págs. 51-61.

Bidaseca, Karina. Negadas a la existencia y condenadas a la desaparición. Un estudio acerca de las luchas de las mujeres rurales en Argentina y Brasil desde la perspectiva de género. En: Ruralidades Latinoamericanas. Identidades y Luchas Sociales. GIARRACA, Norma y LEVY, Bettina. (Comp.). Buenos Aires, Consejo Latinoamericano de Ciencias Sociales, CLACSO, 2004. Págs. 357-418.

Bisang, Roberto. (2003). Apertura económica, innovación y estructura productiva. En: Desarrollo Económico. Revista de Ciencias Sociales. Vol. 43. No 171. Buenos Aires, Instituto de Desarrollo Económico y social. Págs. 413-442.

Boletín algodonero. 2001/2002. En: Indicadores Económicos. Publicación del Departamento de Economía de la Facultad de Ciencias Económicas de la Universidad Nacional del Nordeste. Año 11, Ejemplar No 49, Diciembre de 2002. Pág. 75.

Bourdieu, Pierre.(2000). Las estructuras sociales de la economía. Buenos Aires, Manantial.

Cloquell, Silvia (Coord), Albanesi, Roxana, Propersi, Patricia y otros. (2007). Familias rurales. El fin de una historia en el inicio de una nueva agricultura. Rosario, Homo Sapiens.

Estefanell, Gonzalo; DE BASCO, Mercedes. CIRIO, Félix y OTROS. (1997). El sector agroalimentario argentino en los 90. Buenos Aires, IICA. 166 págs.

Fiorentino, R Ekboir, J.M.; y Lunardelli, L. (1990). La ocupación de mano de obra rural en la Argentina. En: Desarrollo Económico. Revista de Ciencias Sociales. No 119, Vol 30; octubrediciembre de 1990. Buenos Aires, Instituto de Desarrollo Económico y Social,. Pág. 377.

Figueroa, E. y Villapando, F. Estrategias comerciales y productivas en el MERCOSUR Estudio 1.EG.33.5 COMPONENTE b; Préstamo BID 925/OC-AR. Pre II. Coordinación del Estudio. Oficina de la CEPAL-ONU en Bs. As., a solicitud de la Secretaría de Política Económica, Ministerio de Economía de la Nación.

Gago, Alberto y De la torre, Delia. (2001). Globalización y reconversión de la agroindustria alimentaria en la región Cuyo-Argentina. En: Globalización y Territorio. VI Seminario Internacional. Red Iberoamericana de Investigadores sobre Globalización y Territorio. Castagna, Alicia, Raposo, Isabel y Woelflin, María L. (editoras). Rosario, UNR, 2002. Págs. 141-153.

García Pascual, Francisco. (2003). El ajuste estructural neoliberal en el sector agrario latinoamericano en la era de la globalización. En: Revista Europea de Estudios Latinoamericanos y del Caribe. Amsterdam. No 75, octubre de 2003, pp. 3-29.

Gatto, Francisco. (2003). Estudios de Competitividad Territorial. Componente A: Las estrategias productivas regionales. Debilidades del actual tejido empresarial, sistema tecnológico, financiero y comercial de apoyo. Buenos Aires, CEPAL-ONU. 117 págs.

Gatto, Francisco; Centrángolo, Oscar. (2003). Dinámica productiva provincial a fines de los años noventa. Serie Estudios y Perspectivas No 14. Santiago de Chile, CEPAL. 76 págs.

Ghezán, G.; M. Mateos, y J. Elverdin. 2001. Impacto de las políticas de ajuste estructural en el 
sector agropecuario y agroindustrial: el caso de Argentina. Santiago de Chile: CEPAL. Serie Desarrollo Productivo. Número 90.

Larramendy, Juan Carlos y Pellegrino, Luis Alberto. El Algodón. ¿Una oportunidad perdida?. La Plata, Ediciones Al Margen, 2005. 212 págs.

Lattuada, Mario. (2000). El crecimiento económico y el desarrollo sustentable en los pequeños y medianos productores agropecuarios argentinos de fines del siglo $X X$. Versión corregida $\mathrm{y}$ aumentada de la ponencia presentada en las X Jornadas de la Asociación Argentina de Extensión Rural, Mendoza, Argentina, 18-20 de junio de 2000. 23 Págs. Disponible en Internet en: www. rlc.fao.org/foro/institucionalidad/PDF/Lattuada.pdf.

Lattuada, Mario. Movimientos sociales y nuevos actores en la agricultura argentina.El caso del Movimiento de Mujeres Agropecuarias en Lucha (MMAL). Publicado en Revista Internacional de Sociología (RIS), Tercera Epoca, $n^{0}: 30$, Septiembre-Diciembre, 2001, IESA - Consejo Superior de Investigaciones Científicas, Córdoba, España, pág. 107-137, (ISSN: 0034-9712).

Larramendy, J.C. "Si las señales del mercado no son favorables, el productor no volverá a hacer algodón ".Suplemento NORTE RURAL del miércoles 2 de julio de 2003, Resistencia, Chaco. Pág. 7.

Manzanal, Mabel. (1999). La cuestión regional en la Argentina de fin de siglo. En Realidad Económica. IADE, Buenos Aires. Nº 166. Págs. 70-99

Moyano, Eduardo (1994). Acción colectiva y cambio social en la agricultura española. En Papeles de Economía, n 60-61, pp. 234-242.

Pagliettini, L. y Carballo G., C. (2001). El complejo Agroindustrial arrocero argentino en el MERCOSUR. Buenos Aires, Orientación Gráfica Editora, SRL. 236 págs.

Piña, Carlos. (1986: 151). Sobre las historias de vida y su campo de validez en las ciencias sociales. En: Revista Paraguaya de Sociología. Año 23; No 67. Págs. 143-162. Paraguay, Centro Paraguayo de Estudios Sociológicos, 1987.

Rofman, Alejandro. (1995). Economías regionales: Diagnóstico y propuestas. En: Argentina frente a los procesos de integración regional: los efectos sobre el agro. Silvia Cloquell y Eduardo Santos (comps.). Rosario, Homo Sapiens Ediciones. Págs. 229-235.

Rofman, Alejandro. (1999). Economías regionales. Modernización productiva y exclusión social en las economías regionales. En: Revista Realidad económica No 162. Buenos Aires, IADE.

Rofman, Alejandro. (2003). Economías regionales. Perspectivas luego de la devaluación. En: PLAN FENIX. Propuestas para el desarrollo con equidad. Economías Regionales. Tercer Encuentro de Universidades Nacionales. Mendoza, 2003. Facultad de Ciencias Económicas. Universidad Nacional de Cuyo. Págs. 383-411.

Rofman, Alejandro. (2004). Antecedentes, requisitos y contenido mínimo de un plan nacional de desarrollo rural territorial. En: Plan Fénix. Propuestas para el desarrollo con equidad. Foro Permanente del Complejo Agroindustrial Alimentario en el marco del Plan Fénix. Estrategias y Políticas Nacionales.Buenos Aires, Facultades de Agronomía, Ciencias Económicas, Ciencias Exactas y Naturales, Ciencias Veterinarias, Farmacia y Bioquímica de la Universidad de Buenos Aires.

Rofman, Alejandro y García, Liliana. .(2007). El desarrollo de las campañas algodoneras entre los años 2001 y 2005. Los encadenamientos productivos y la situación de los agentes económicos en el proceso de estancamiento y/o deterioro de la actividad. En: $\mathrm{V}^{\mathrm{o}}$ Jornadas Interdisciplinarias de Estudios Agrarios y Agroindustriales. Buenos Aires, Facultad de Ciencias Económicas, UBA, disponible en CD . ISSN: 1851-3794.

Sánchez Hernández, José Luis. (2003). Naturaleza, localización y sociedad. Tres enfoques para la 
geografía económica. Salamanca. Ediciones Universidad de Salamanca.

Santos Milton. (2000). La naturaleza del espacio. Barcelona, ARIEL, 348 págs.

Sepúlveda, S.; Rodríguez, A.; Echeverri, R. y otros. (2003). El enfoque territorial del desarrollo rural. Costa Rica, Instituto Interamericano de Cooperación para la Agricultura. 156 págs.

Valenzuela, Cristina. Los agentes locales del desarrollo rural. El accionar de las organizaciones cooperativas y solidarias, el sector empresario y el estado provincial, en la dinámica agrícola de los '90 en el Chaco. En: Desarrollo Rural. Organizaciones, instituciones y territorios - Enfoques y experiencias”. Manzanal,M; Neiman, G. y Lattuada, M. Buenos Aires, CICCUS, 2005.

Valenzuela, Cristina. Transformaciones agrarias y desarrollo regional en el nordeste argentino. (una visión geográfica del siglo XX). Buenos Aires, Editorial La Colmena, 2006, 186 págs.

Valenzuela, Cristina. Transformaciones y conflictos en el sector agrícola del Chaco en los '90: articulaciones territoriales de una nueva racionalidad productiva. Editado en: Mundo Agrario, No 10, ISSN 1515-5994, 2005. Disponible en Internet en: http://163.10.30.203:9673/ mundo_agrario/numeros/numero10/.

\section{Fuentes}

Entrevistas en profundidad con respuestas abiertas realizadas el 13/07/06, el 21/11/06 y el 23/11/06, a la dirigente de la Organización Mujeres de la Producción Juana Vukich.

Entrevistas en profundidad con respuestas abiertas a: Vicente Benjamín Verón, Juan Lesemesuc y Pablo Dworak, productores algodoneros del Lote 33 Pampa Napenay y a Eduardo Nichiporuk y Héctor Capitanich, productores del Lote 1 Colonia José Mármol ( La Montenegrina).

Mujeres de la Producción reclaman un subsidio para el sector agropecuario. Fuente: Diario PRIMERA LÍNEA. Disponible en : http://chaco.derf.com.ar/despachos.asp?cod des=498\&ID_Seccion=5111 de setiembre de 2006

Productores vuelven con sus reclamos ante el Banco Nación en Campo Largo. Lunes, 16 de enero del 2006. Disponible en: http://www.corrientesnews.com.ar/interior.php?nid=19905

Temor y alerta en el campo: Siguen los remates. Diario Norte. Domingo, 18 de diciembre del 2005. http://www.corrientesnews.com.ar/interior.php?nid=16743.

Diario Norte: 3/10/06. Disponible en: http://www.cuencarural.com/noticias/mujeres_de_la produccion_no_acompanara_a_faa/

Diario NORTE: Versión impresa:

Suplemento CHACO ADENTRO, Diario Norte: 8,11, 13,15, 16 y 26 de marzo de 2001, 30 de abril de 2003, 6, 7, 28 y 29 de abril de 2005 y 22 de junio de 2007.

Suplemento CHAQUEÑA: del 7 de marzo de 2004 y del 10 de Abril de 2005, págs. 4 y 5.

Suplementos NORTE RURAL 30 de junio de 1999, Pág. 5; 26 de enero de 2000. Pág. 5; del miércoles 16 de febrero de 2000, pág. 5. ; $1^{\circ}$ de marzo de 2001.págs. 4 y 5.28 de noviembre de 2001; 15 de mayo de 2002, pág. 2. ; 18 de mayo de 2003, pág. 2, 2 de julio de 2003,. Pág. 7.; 8 de octubre de 2003, pág. 3.; 31 de diciembre de 2003, pág. 2; 19 de marzo de 2003, pág. 3; del 30 de abril de 2003, pág. 3; 27 de agosto de 2003, pág. 5; 8 de octubre de 2003,14 de abril de 2004, pág. 7; 2 de junio de 2004, pág. 6.10 de agosto de 2004; pág. 5; 3 de octubre de 2006 y 2 de diciembre de 2007, págs. 4 y 5.

PROVINCIA DEL CHACO. Ministerio de la Producción. Subsecretaría de Ganadería y Granja. Estadísticas Ganaderas y Granjeras. Resistencia, 1998 y 2004. 


\title{
Resumen
}

El trabajo expone la dinámica de la actividad agrícola del Chaco, jurisdicción que exhibió en los últimos diez años, la coexistencia de dos modalidades diferenciadas de manejo productivo. En esta provincia del nordeste de la República Argentina, conviven desde fines de la década del noventa, los esquemas tradicionales de tipo familiar arraigados históricamente al cultivo algodonero como práctica heredada por generaciones y los nuevos modelos y estrategias diferenciadas de apropiación y uso del suelo asociados a la soja transgénica y su tecnología de insumos y procesos. El estudio de esa realidad requiere el examen multiescalar de las dos lógicas de actuación lo cual implica examinar el contexto nacional para luego bajar a la dinámica provincial y en última instancia llegar a la escala del individuo para completar el análisis y la interpretación de las diferentes posturas de los agentes que construyen esa trama.

$<$ Procesos productivos $><$ Territorialidad $><$ Dialéctica multiescalar $>$

\begin{abstract}
This paper exposes the dynamics of the agricultural activity of Chaco, jurisdiction that it exhibited in last the ten years, the coexistence of two modalities differentiated from productive handling. In this province of the northeast of the Argentine Republic, they coexist from Nineties ends, the traditional schemes of familiar type associated historically to practical the cotton culture as inherited by generations and the new models and strategies differentiated from appropriation and use of the ground associated the transgenics soybean and its technology of processes. The study of that reality requires the examination to multiscale of the two logics of performance which implies to examine the national context soon to lower to provincial dynamics and in last instance to arrive at the scale of the individual to complete the analysis and the interpretation of the different positions from the agents who construct that structure.
\end{abstract}

$<$ Productive processes $><$ Territories $><$ Dialectic to multiscale $>$ 